\title{
Research on mushroom yields in Finland
}

\section{ESTERI OHENOJA}

OHENOJA, E. 1978: Research on mushroom yields in Finland, 1976-78. - Karstenia 18 (suppl.).

A research project to study mushroom yields in Finland was instituted in 1976 with support from the Academy of Finland and the Forest Research Institute, the purpose being to establish the quality and quantity of the autumn mushroom yield in different parts of the country and to determine the timing of the mushroom season. Although the main emphasis is placed upon the 'commercial species', other edible and also the poisonous fungi are included in the study. In the case of the commercial species the value of the yields is al so to be estimated.

The basis of the work is a series of 250 stable experimental plots $(2 \times 50 \mathrm{~m})$ situated in 30 localities in different parts of Finland, from which all fungal fruiting bodies are collected at weekly intervals from July to October. These are then weighed and counted by species. A large proportion of the material is dried, and identification to species may be based on elther fresh or dried samples. The plots concerned are in most cases located on mineral soll in various types of heath forest, the types selected representing those most prevalent in the area in question.

Some surveys are also carrled out on ad hoc lines set up through the forest. Certain ecological moasurements are also being performed.

Mushroom yields were poor throughout the country in autumn 1976, with little regional variation. Even in the case of the edible fungl the differences in yleld between Southern and Northern Finland, for Instance, were very small. The ylelds in 1977, however, represent peak figures in Southern Finland and a better than average year in the north.

E. Ohenoja, Department of Botany, University of Oulu, SF-90100 Oulu 10, Finland. 